\title{
Outcome of Endoscopic Third Ventriculostomy in Infants
}

\author{
Elsayed M. Aboelhasan ${ }^{1 *}$ M.B.B.Ch; Abdelhaleem A. Mousa ${ }^{1}$ MD; Islam M. $\operatorname{Alaghory}^{1}$ MD;
}

\author{
*Corresponding Author: \\ Elsayed M. Aboelhasan \\ dr.sma.87@gmail.com
}

Received for publication March 11,2021;Accepted March 31, 2021; Published online March 31, 2021.

\section{Copyright 2020 The Authors published by Al-Azhar} University, Faculty of Medicine, Cairo, Egypt. All rights reserved. This an open-access article distributed under the legal terms, where it is permissible to download and share the work provided it is properly cited. The work cannot be changed in anyway or used commercially.

doi: 10.21608/aimj.2021.67341.1434

${ }^{1}$ Neurosurgery Department, Faculty of medicine, Al-Azhar university, Cairo, Egypt.

\begin{abstract}
Background: Hydrocephalus in infancy is usually treated with a ventriculo-peritoneal (VP) shunt, however, endoscopic third ventriculostomy (ETV) is a recent surgical option of treatment which if succeeded, avoids shunt insertion complications.

Aim of the work: to analyze the OUTCOME of ETV as a treatment for hydrocephalus in infants aged less than 1 year.

Patients and methods: An analytical prospective study conducted on 40 infants suffering from obstructive hydrocephalus (28 infants with congenital aqueductal stenosis and 12 infants with post meningitic hydrocephalus) in infants younger than one year of age treated via ETV approach in Al Azhar university hospitals in the period September 2017 to September 2020. Follow up of patients done clinically and radiologically over 6 months.

Results: The clinical success rate in our study was achieved in 22 cases (55\%) while failure was encountered in the remaining 18 cases (45\%) When comparing successful and failed cases, no significant difference was detected between the two groups regarding patient age $(p=0.095)$. Conversely, it was evident that the prevalence of post-meningitic stenosis was significantly more common in the failed group (44.44\% vs. $18.18 \%$ in the successful group $-\mathrm{p}<0.001)$. Success rates were significantly different in infants with aqueductal stenosis 18case (81.82\%).

Conclusion: ETV can be the definitive treatment for obstructive hydrocephalus with different etiologies in infants less than one year of age. Success rate of ETV depends not only on the age but mainly on the cause of hydrocephalus, preoperative MRI findings and surgeon endoscopic experience.
\end{abstract}

Keywords:endoscopic third ventriculostomy; obstructive hydrocephalus ; pediatric neurosurgery.

Disclosure: The authors have no financial interest to declare in relation to the content of this article. The Article Processing Charge was paid for by the authors.

Authorship: All authors have a substantial contribution to the article.

\section{INTRODUCTION}

Hydrocephalus is a major cause of morbidity in the paediatric population, with an estimated prevalence of 1.2 in every 1000 children. In children, untreated hydrocephalus can have severe consequences including developmental problems, learning difficulties, and blindness. ${ }^{1}$

Traditionally, shunts have been used as the main treatment strategy for hydrocephalus. More recently, endoscopic third ventriculostomy (ETV) has emerged as a method of treatment for noncommunicating hydrocephalus ${ }^{(2)}$.

ETV has been used on pediatric patients with aqueduct stenosis in many centers because of its advantage of providing a naturalflow route for cerebrospinal fluid (CSF) within the range of indications. The long-term success rate has been reported to be as high as $80 \%$, however, according to some reports on ETV, children younger than 6 months have a lower success rate of $12.5 \%{ }^{3}$

\section{PATIENTS AND METHODS}

A written informed consent was taken from all participation after proper explanation of the study.An analytical prospective study conducted on 40 infants suffering from obstructive hydrocephalus (28 infants with congenital aqueductal stenosis and 12 infants with post meningitic hydrocephalus) in infants younger than one year of age treated via ETV approach in Al Azhar university hospitals in the period September 2017 to September 2020. Follow up of patients done clinically and radiologically over 6 months.

Inclusion criteria

Age of one year or less.

Obstructive hydrocephalus (Aqueductal stenosis).

Exclusion criteria

History of previousprocedure CSF diversion

History of recent intracranial hemorrhage 
History ofrecent central nervous system (CNS) infection or septicemia

Associated myelomeningocele (Chiari malformation type II).

History of blood and bone marrow diseases

Endoscopic equipment:

$G A A B{ }^{\circledR}$ system: It consists basically of an outer operating sheath with $6.5 \mathrm{~mm}$ diameter within which fits an obturator for cannulation of the ventricular system. The obturator is then replaced with operating telescope (0 degree) that has single working channel. The head of the telescope is attached to the camera and light source.

LOTTA® system:. It consists of an outer operating sheath with $6.8 \mathrm{~mm}$ diameter within which fits an obturator for the ventricular system; Cannulation. The obturator is then replaced with operating telescope (6 degree) that has main working channel and two suction/irrigation channels that can permit $1.6 \mathrm{~mm}$ flexible (second) long instrument.

\section{General operative steps:}

General anaesthesia was used in all cases

Most of the procedures were performed using precoronal burr hole with the patient in supine position having head resting on headrest and slightly elevated (20 degrees). A standard right side burr hole at Kocher's point $(3 \mathrm{~cm}$ lateral to midline and $1 \mathrm{~cm}$ anterior to coronal suture) was adopted. A left, instead of right side was used in only one case of ventricular asymmetry with wider left lateral ventricle.

\section{A single burr hole was used in all cases}

A small skin flap was designed around the site of the burr hole.

A small burr hole (slightly less than $10 \mathrm{~mm}$ ) was adopted. Free hand ventricular system cannulation was followed using the trochar in and $G A A B \AA$ system.

Endoscopic third ventriculostomy (ETV):

The third ventricle was entered and the following structures were identified: paired mammillary bodies, dorsum sellae, infundibular recess and pulsating basilar artery. Generally, the stoma was placed in the tuber cinereum midway between infundibular recess and mammillary bodies just behind the dorsum sellae and avoiding the basilar artery. Blunt perforation was always the rule (even with tough floor) using monopolar forceps or Fogarty catheter. Following perforation, the stoma was dilated using size 3 French Fogarty catheter to achieve a fenestration size of at least $5 \mathrm{~mm}$. Theprepontine and interpeduncular cisterns were then inspected for any second membrane which if present was also perforated and dilated applying the same principles. On completion of the procedure the operating sheath is withdrawn with the endoscope inside to look for any active bleeding.

Postoperative course:
Patients were usually discharged to ordinary ward and kept in bed with head elevated 20 degrees. Patients were observed clinically according to the following protocol:

Neurological evaluation:

Resolution of their clinical symptoms

Appearance of manifestations of intracranial hypertension

Occurrence of any early postoperative complications as fever, a change in conscious level, fits, third nerve palsy, CSF leak, hemiparesis, wound dressing.

Evaluation of the general state e.g. vital signs, chest, cardiac condition...etc.

Evaluation of the wound.

Follow up and outcome

Clinical visits

Patients were evaluated once weekly for the 4 week then monthly for the 3 months and the patients were finally evaluated at the end of the 6 month postoperatively.

Postoperative imaging

CT brain was obtained in all patients within the first week or if the patient showed any clinical deterioration. CT brain was also done immediately in any patient presented with recurrence of their symptoms(18 cases) during the follow up period. MRI CSF flowmetry of the brain was obtained at the end of third month postoperatively for (4 cases ) in whom their previous neuroimages didn't reveal significant change without clinical improvement.

\section{ETV Success}

ETV is generally considered successful when clinical success is observed after 3 months postoperatively without the need for re-ETV or shunting. This postoperative time range is essential because most failures occur within this short interval ${ }^{(4)}$.

ETV failure was defined clinicallyas children in whom clinical symptoms of hydrocephalus did not regress and as children who required additional neurosurgical treatment for hydrocephalus.

Statistical analysis of the data

The collected data were coded, processed and analyzed using the SPSS (Statistical Package for Social Sciences) version 26 for Windows ${ }^{\circledR}$ (IBM SPSS Inc, Chicago, IL, USA). Data were tested for normal distribution using the Shapiro Walk test. Qualitative data were represented as frequencies and relative percentages. Quantitative data were expressed as mean \pm SD (Standard deviation)/ Median (Range).Independent samples t-test was used to compare between two independent groups of normally distributed variables (parametric data). Univariate regression analysis was used to test predictors (or risk factors) for binary categorical outcome. Independent predictors (or risk factors) were identified from the significant univariate analysis by using multivariate regression analysis.Level of significance: Significance test results are quoted as two-tailed probabilities.For all the above-mentioned tests, the level of significance was 
tested, expressed as the probability of (p-value) and the results were explained as following: Significant if the $\mathrm{p}$ value is $\leq 0.05$.

\section{RESULTS}

A prospective study of 40 infants who were diagnosed for the first time with obstructive hydrocephalus due to aqueduct stenosis with different etiologies has been performed at the period from September 2017 to September 2020.Patients have been operated in neurosurgical department of Al-Azahr University Hospitals. During the period of study, we operated upon 40 patients. The mean age of the included cases was 7.73 months (range, 2-12 years). Most of the included cases were older than 6 months (80\%). We included 24 males (60\%) together with 16 females (40\%).

The common cause of hydrocephalus in our study was congenital aqueductal stenosis (28 cases - 70\%), followed by post-meningitic stenosis (30\%).

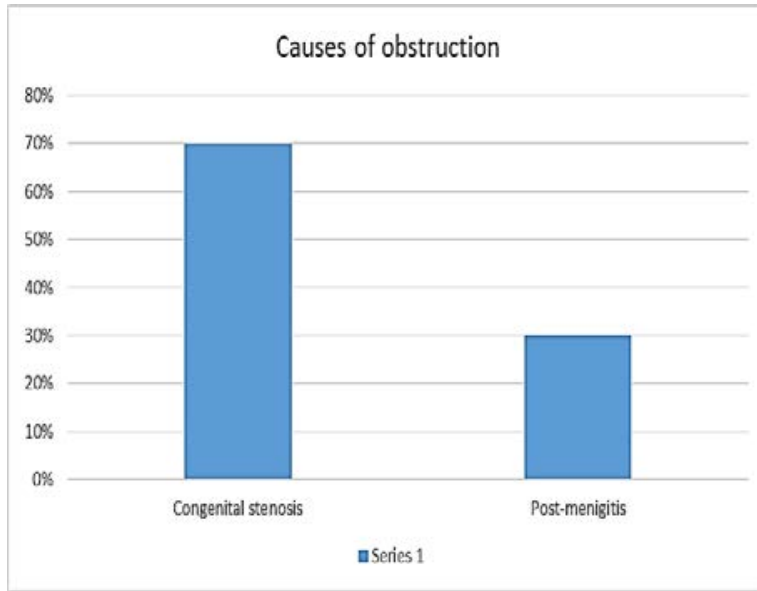

Fig. 1: Causes of obstruction in the cases of the study.

The mean duration of operation was 35 minutes (range, 20 - 48 minutes).

\begin{tabular}{|c|c|c|}
\hline \multirow{2}{*}{ Items } & \multicolumn{2}{|c|}{ Study cases $n=40$} \\
\hline & Number & Percent (\%) \\
\hline \multicolumn{3}{|c|}{ Operative time (Minutes) } \\
\hline Mean \pm SD & \multicolumn{2}{|c|}{$35 \pm 8.36$} \\
\hline Median (Range) & \multicolumn{2}{|c|}{$37(20-48)$} \\
\hline
\end{tabular}

Table 1: Operative data of the subjects in the study.

Categorical data expressed as Number (\%)

Continuous data are expressed as mean \pm SD median (Min-Max)

All of the presented cases had head enlargement (100\%), while history of fever was reported in the 12 cases (30\%) with post-meningitic stenosis. In addition, seizures were reported by 10 cases (25\%), whereas vomiting was experienced in only 5 cases (12.5\%).

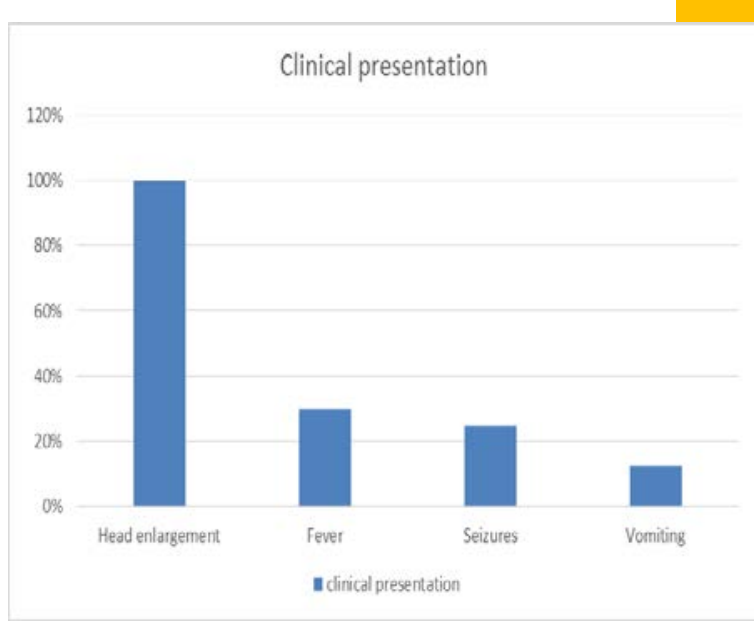

Fig. 2: Clinical presentation of the included cases. As regard post-operative complications, meningitis was detected in 2 cases (5\%), while CSF leak occurred in 8 cases $(20 \%)$. Both of the previous complications were successfully managed by conservative treatment. New onset seizures were reported by 3 cases $(7.5 \%)$

Success was achieved in 22 cases (55\%), while failure was encountered in the remaining ones (45\%).

\begin{tabular}{||l|c|c||}
\hline \multirow{2}{*}{ Items } & \multicolumn{2}{|c|}{$\begin{array}{c}\text { Study cases } \\
\mathbf{n = 4 0}\end{array}$} \\
\cline { 2 - 3 } & Number & Percent(\%) \\
\hline \hline Final outcomes \\
\hline Failed & 18 & 45 \\
\hline Success & 22 & 55 \\
\hline
\end{tabular}

Table 2: Final outcomes of the subjects in the study. Categorical data expressed as Number (\%).

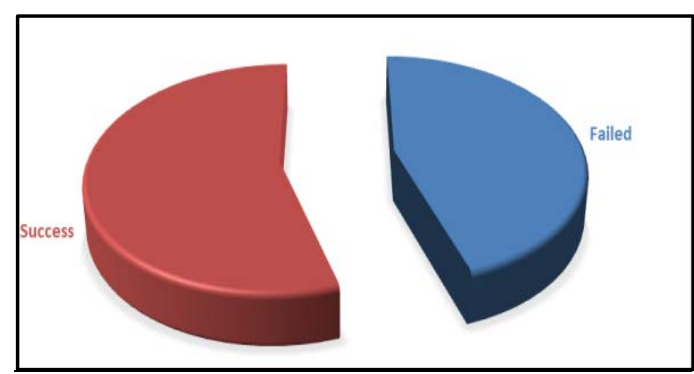

Fig. 3: Final outcomes of the cases of the study. When comparing successful and failed cases, no significant difference was detected between the two groups regarding patient age $(\mathrm{p}=0.095)$. Conversely, it was evident that the prevalence of post-meningitic stenosis was significantly more common in the failed group (44.44 vs. $18.18 \%$ in the successful group $-\mathrm{p}$ $<0.001)$.

\begin{tabular}{||l|l|l|l||}
\hline & $\begin{array}{c}\text { Success }(\mathbf{n}= \\
\text { 22) }\end{array}$ & \multicolumn{1}{|c|}{$\begin{array}{c}\text { Failure }(\mathbf{n}= \\
\text { 18) }\end{array}$} & $\begin{array}{c}\text { P } \\
\text { value }\end{array}$ \\
\hline \hline Age & & & 0.095 \\
$-<6$ months & $3(13.64 \%)$ & $5(27.78 \%)$ & \\
$->6$ months & $19(86.36 \%)$ & $13(72.22 \%)$ & \\
\hline Indication & & & $<$ \\
-Congenital & $18(81.82 \%)$ & $10(55.56 \%)$ & 0.001 \\
stenosis & $4(18.18 \%)$ & $8(44.44 \%)$ & \\
-Post-meningitis & & & \\
\hline
\end{tabular}

Table 3: Comparing failed with successful cases. 


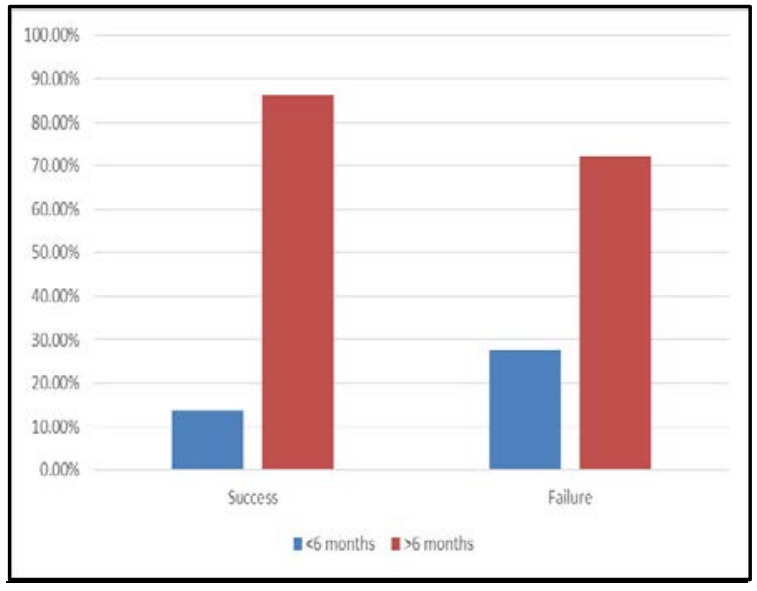

Fig. 4: Comparing age in success and failure groups.

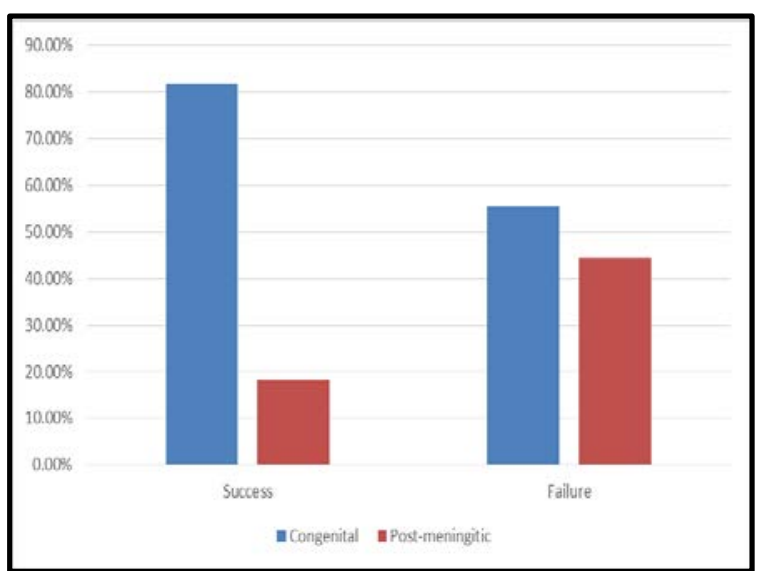

Fig. 5: Comparing indication in success and failure groups.

Univariate analysis revealed that age less than 6 months and post-meningitic stenosis were risk factors for failure ( $\mathrm{p}<0.05$ ). However, only the latter one was independent predictors for failure on multivariate analysis $(\mathrm{p}=0.005)$.

\begin{tabular}{|c|c|c|c|c|c|}
\hline \hline \multirow{2}{*}{ Predictors } & $\begin{array}{c}\text { Univariate } \\
\text { regression } \\
\text { analysis }\end{array}$ & \multicolumn{4}{|c|}{ Multivariate regression analysis } \\
\cline { 2 - 6 } & $\begin{array}{c}\mathbf{P} \\
\text { value }\end{array}$ & $\begin{array}{c}\mathbf{P} \\
\text { value }\end{array}$ & OR & \multicolumn{2}{|c|}{$\mathbf{9 5 \%}$ C.I. for OR } \\
\cline { 5 - 6 } & & & Lower & Upper \\
\hline \hline $\begin{array}{r}\text { Age }<6 \\
\text { months }\end{array}$ & $\mathbf{0 . 0 3 5 *}$ & 0.087 & 1.465 & 0.96 & 1.82 \\
\hline $\begin{array}{r}\text { Male } \\
\text { gender }\end{array}$ & 0.108 & & & & \\
\hline $\begin{array}{r}\text { Meningitic } \\
\text { stenosis }\end{array}$ & $\mathbf{0 . 0 0 5 *}$ & $\mathbf{0 . 0 0 3}^{*}$ & 1.824 & 1.273 & 2.982 \\
\hline \hline
\end{tabular}

Table 4: Regression analysis to detect risk factors of ETV failure.

\section{Case presentation}

A 7 months old female patient presented to the hospital by manifestations of increased ICP and on neurological examination, patient was fully conscious, normal motor and sensory systems and no cranial nerve affections with normal gait, but his fundus examination showed established papilledema.
MRI brain showing severe hydrocephalus with asymmetry (Fig. 6).
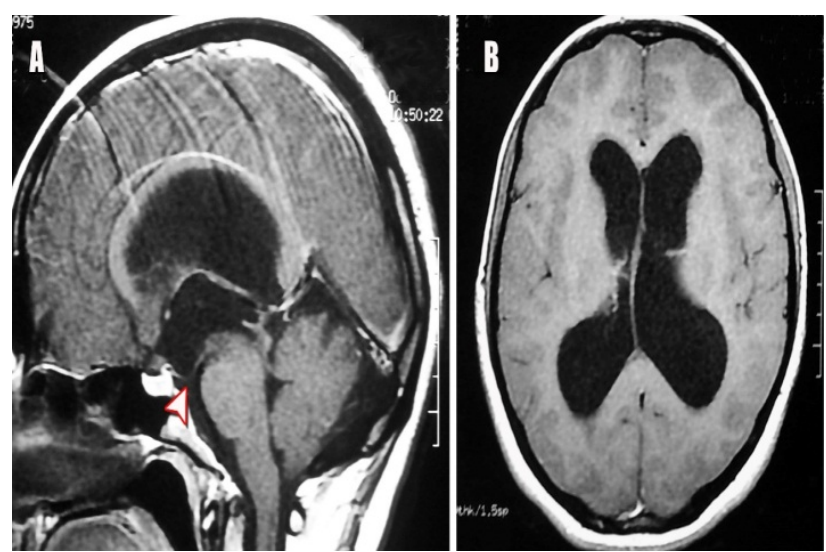

Fig. 6:

(A): Preoperative sagittal T1 MR image with contrast showing hydrocephalus caused by Primary aqueductal stenosis, downward bulgingthe third ventricle floor (white arrow head).

(B): Pre-operative to T1 axial MR image showing severe hydrocephalus with asymmetry.

Endoscopic third ventriculostomy (ETV) surgery was done, without intraoperative complications. After surgery, manifestations of increased intracranial pressure were relieved. (Fig.7).
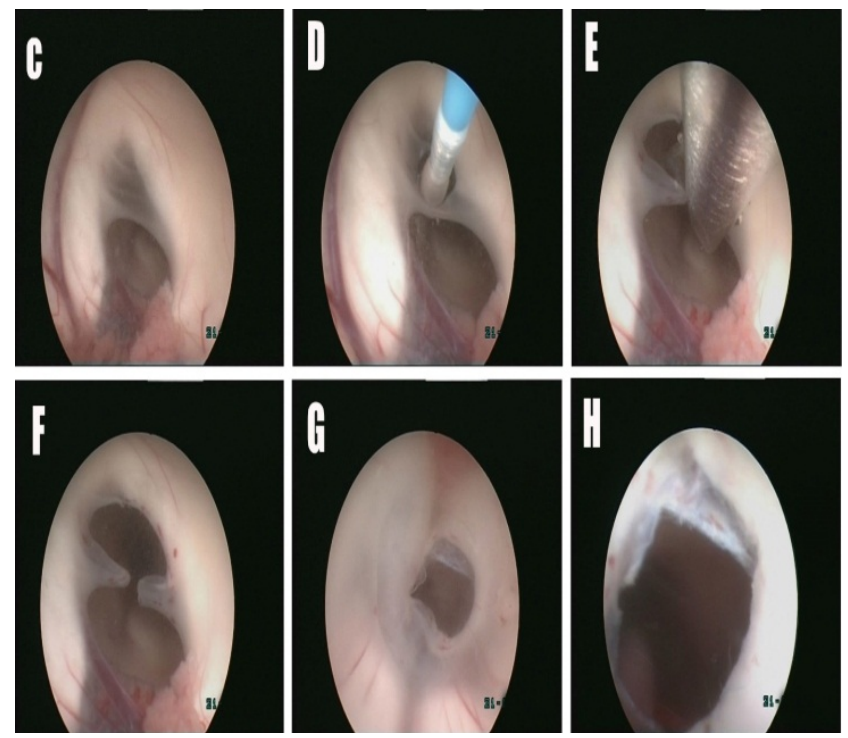

Fig. 7: Intra-operative images

(C): Membranous partial obstruction of the foramen of Monro.

(D): Balloon Foraminoplasty.

(E): Using the scissor to achieve cutting of remaining band.

(F): Foraminoplasty mission completed.

(G): floor of the third ventricle showing ETV with

Lilliquist's membrane underneath.

$(\mathrm{H})$ : Closer up view on the stoma showing the basilar artery and full patency. 

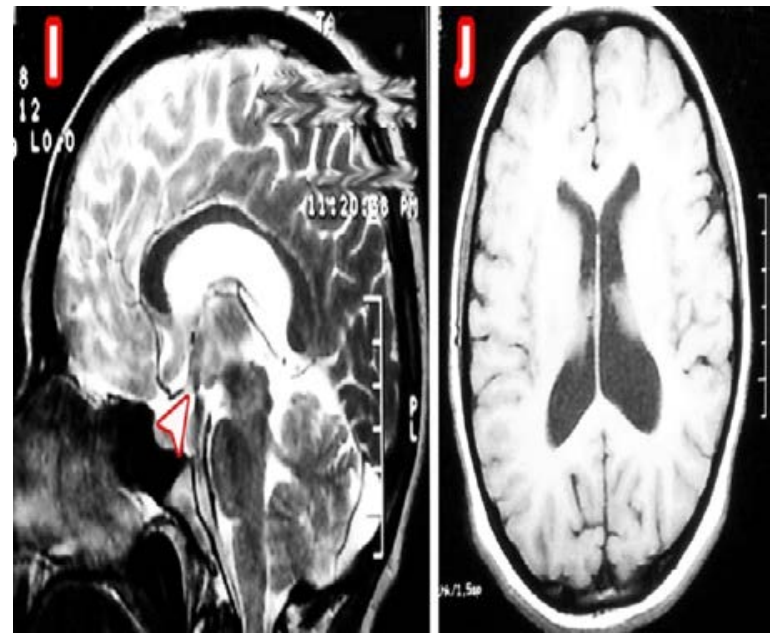

Fig. 8: Postoperative images.

(I): $\quad$ A sagittal T2 MR image showing marked signal void of patent ETV in the floor of the third ventricle.

(J): Axial T1 MR image showing a decline in the diameter of both third and lateral ventricles.

\section{DISCUSSION}

In this prospective study, we investigated the outcome of ETV as a primary treatment for obstructive hydrocephalus caused by aqueduct stenosis in infants. The mean age of the current studied cases was7.73 months (range, 2 - 12 months), $40 \%$ were females and $60 \%$ were males.

The clinical success rate in our study was achieved in 22 cases (55\%) while failure was encountered in the remaining 18 cases (45\%) When comparing successful and failed cases, no significant difference was detected between the two groups regarding patient age $(p=0.095)$. Conversely, it was evident that the prevalence of post-meningitic stenosis was significantly more common in the failed group $(44.44 \%$ vs. $18.18 \%$ in the successful group $-\mathrm{p}<$ 0.001 ). Success rates were significantly different in infants with aqueductal stenosis 18 cases (81.82\%). The largest study of ETV success in very young children was conducted in Uganda and involved 153 children younger than one year. The ETV success rate among these patients was 53\%. The surgery success rates for patients with aqueductal obstruction and myelomeningocele were 40 and $70 \%$, respectively. $^{5}$

Fritsch et al. ${ }^{6}$ reporting a 39\% ETV success rate, present ETV as an effective alternative for the treatment of obstructive hydrocephalus in infants younger than one year. The authors note that age does not present a contraindication for ETV or increase the perioperative risk. They conclude that the success of ETV is determined by the cause of hydrocephalus.

Alaghory et al. ${ }^{7}$ reporting The clinical success rate of ETV was 56\%.These results are comparable to other studies. Success rate of $61 \%$, 64\%and 55\%was observed in other studies done in infants while the success rate in other age group patients varied from 76\%to 91.5\% Failure of ETV was 44\% including one procedure which was abandoned (2\%) due to poor visualization of the floor of the third ventricle.

\section{CONCLUSION}

Our study confirmed that ETV can be the definitive treatment for obstructive hydrocephalus with different etiologies in infants less than one year of age. Success rate of ETV depends not only on the age but mainly on the cause of hydrocephalus, preoperative MRI findings and surgeon endoscopic experience

Finally, this conclusion needs furthermore documentation by studying a large randomized study series of patients

\section{REFERENCES}

1. Kahle KT, Kulkarni AV, Limbrick Jr DD, Warf BC. Hydrocephalus in children. The lancet. $2016 \mathrm{Feb}$ 20;387(10020):788-99.

2. Zaben M, Manivannan S, Sharouf F, Hammad A, Patel C, Bhatti I, Leach P. The efficacy of endoscopic third ventriculostomy in children 1 year of age or younger: A systematic review and metaanalysis. European Journal of Paediatric Neurology. 2020; 1;26:7-14.

3. Zohdi AZ, El Damaty AM, Aly KB, El Refaee EA. Success rate of endoscopic third ventriculostomy in infants below six months of age with congenital obstructive hydrocephalus (a preliminary study of eight cases). Asian J Neurosurg 2013;8:147-52.

4. Vulcu S, Eickele L, Cinalli G, Wagner W and Oertel J. Long-term results of endoscopic third ventriculostomy: an outcome analysis. Journal of neurosurgery. 2015; 123: 1456-62.

5. Warf BC, Stagno V and Mugamba J. Encephalocele in Uganda: ethnic distinctions in lesion location, endoscopic management of hydrocephalus, and survival in 110 consecutive children. Journal of Neurosurgery. 2011; 7: 88-93.

6. Fritsch $\mathrm{M}$, Kienke S, Ankermann T, Padion M, Mehdorn M. Endoscopic third ventriculostomy in infants. J Neurosurg 2005; 103:50-3.

7. Behairy H, Alaghory I, Hassan M, Ragab A, Barania M, Ellabbad M. Endoscopic third Ventriculostomy (ETV) in infants. Is it contraindicated?. Journal of American Science. 2015; 11(4):218-22. 